\title{
OS EFEITOS DA PANDEMIA NOS HÁBITOS COMUNITÁRIOS: UM ESTUDO DE CASO SOBRE A FEIRA LIVRE (PÁTIO NOVO) DO BAIRRO DE AFOGADOS EM RECIFE/PE
}

\author{
https://dx.doi.org/10.48097/2674-8673.2022n6p15
}

\author{
Magali Ferreira de Menezes ${ }^{1}$ \\ Fábio José de Araújo Pedrosa²
}

\section{RESUMO}

As feiras livres fazem parte do cotidiano social nas grandes metrópoles ou nos lugarejos mais longínquos. A pergunta norteadora foi: a pandemia da Covid-19 causou alguma mudança positiva no comportamento dos feirantes do Pátio Novo da Feira Livre de Afogados (PNFLA), no tocante aos hábitos de limpeza e higiene dos feirantes? A coleta de dados ocorreu no período de 23/10/21 a 21/11/21. Foram entrevistados 55 feirantes. O questionário foi o método de coleta de dados. $26 \%$ dos respondentes tinham idade entre 41 e 50 anos e $11 \%$ tinham mais de 60 anos. $53 \%$ são escolarizados e 9\% concluíram o ensino médio. $43 \%$ atuam há mais de 20 anos e $2 \%$ entre 01 e 05 anos. Os proprietários representaram 51\% dos entrevistados e $11 \%$ são feirantes funcionários. Os feirantes têm conhecimento sobre a existência do coronavírus e têm pouca segurança ao afirmarem que conhecem ou desconhecem as formas de contágio. As pessoas que trabalham na feira livre não tiveram suporte técnico e sanitário satisfatório por parte da Prefeitura do Recife para enfrentar a pandemia. Como proposta para pesquisas futuras, propõem-se expandir o estudo para outras feiras livres da região metropolitana do Recife e de outras capitais.

Palavras-chave: Feira livre. Pandemia. Mudança de hábitos. Higiene.

Data de submissão: 22/12/2021

Data de aprovação: 30/12/2021

\section{RESUMEN}

Las ferias libres son parte de la vida social cotidiana en las grandes ciudades o en las regiones longincuas. La pregunta orientadora fue: ¿la pandemia de la covid-19 provocó algún cambio positivo en el comportamiento de los feriantes en el Patio Nuevo de la Feria Libre de Afogados (PNFLA), en relación a los hábitos de limpieza e higiene de los feriantes? La recolecta de datos fue hecha en el periodo comprendido entre el 23/10/21 y el 21/11/21. Se entrevistó a 55 feriantes. El cuestionario fue el método utilizado para la recolecta de datos. El 26\% de los encuestados tienen entre 41 y 50 años y el 11\% tienen más de 60 años, el 53\% son escolarizados y el $9 \%$ han concluido la enseñanza media, el $43 \%$ actúan hace más de 20 años y el $2 \%$ entre 01 y 05 años. Los propietarios representan el 51\% de los encuestados y el 11\% son feriantes

\footnotetext{
${ }^{1}$ Mestra em Gestão do Desenvolvimento Local Sustentável pela Universidade de Pernambuco.

E-mail: magalimenezes@gmail.com

${ }^{2}$ Professor Adjunto da Universidade de Pernambuco e da Universidade Católica de Pernambuco.

E-mail: fabio.eco@terra.com.br
} 
empleados. Los feriantes tienen conocimiento de la existencia del coronavirus y tienen poca seguridad al afirmar que conocen o desconocen las formas de contagio por el nuevo coronavirus. Las personas que trabajan en la feria libre no recibieron soporte técnico y sanitario satisfactorio por parte del ayuntamiento de Recife para enfrentar la pandemia. Como propuesta para investigaciones futuras, se propone ampliar el estudio a otras ferias libres de la región metropolitana de Recife y otras capitales.

Palabras clave: Feria libre. Pandemia. Cambio de habito. Higiene.

\section{INTRODUÇÃO}

Quer conhecer os hábitos de um lugar? Então, entre outras coisas, visite a Feira Livre (FL) e irá descobrir do que costumam se alimentar e a forma com que tratam os seus alimentos.

As FL fazem parte do cotidiano social brasileiro, seja nas grandes metrópoles ou nos lugares mais longínquos. Elas aglutinam pessoas, esbanjam cultura e tradição local. É fonte de renda para muitas famílias e contribui de forma significativa para a saúde coletiva daqueles que de lá se abastecem de frutas, legumes, carnes, pescados, entre outros.

No Brasil, o primeiro e único censo demográfico das Feiras Livres (FL) ocorreu em 2014. $\mathrm{Na}$ ocasião, o relatório indicou o funcionamento de 5.119 feiras livres espalhadas em 1.176 municípios (MDS, 2015), ou seja, um número bastante expressivo para que apenas 01 censo tenha sido realizado, tendo em vista que são parte integrante e muito importante na geração de renda de muitas famílias.

A ausência de realização do censo nas FL colabora diretamente para a falta de controle na ocupação do espaço público, controle sanitário, trabalho infantil, prostituição, venda de drogas e outros tipos de violência.

Considera-se que as FL empregam desde o pequeno agricultor até famílias inteiras, bem como empregos diretos para feirantes, sendo eles donos dos bancos ou empregados e, não menos importante, destacar também a contribuição da FL na segurança alimentar da população.

Em qualquer localidade do Brasil, por menor que seja, tem uma FL. Faz parte do cotidiano dos brasileiros ir à feira em busca de alimentos frescos, com preço acessível e variedade de produtos.

Em estudo recente, Menezes, Freitas e Pedrosa (2021, no prelo) trataram sobre as FL da região Nordeste do Brasil, em cenário anterior à pandemia do novo coronavírus, tendo como estado da arte a confirmação da difícil realidade sanitária vivenciada nes ses centros comerciais.

Dessa forma, a expertise dos autores sobre sustentabilidade ambiental impulsiona a continuidade das pesquisas sobre essa temática. Assim, elegeu-se como pergunta norteadora desse estudo: a pandemia da Covid-19 causou alguma mudança positiva no comportamento dos 
feirantes do Pátio Novo da Feira Livre de Afogados (PNFLA), no tocante aos hábitos de limpeza e higiene dos feirantes? Para tanto, foram eleitos os seguintes objetivos específicos: a) verificar a presença de material gráfico orientativo disponibilizado pelos órgãos sanitários do governo estadual e/ou municipal sobre o combate ao novo coronavírus e/ou as diversas formas de contágio; b) identificar a forma de descarte dos resíduos secos e molhados por parte dos feirantes; c) analisar a percepção dos feirantes sobre a relação entre a limpeza e conservação do ambiente físico e o combate ao novo coronavírus.

\section{REFERENCIAL TEÓRICO}

A primeira pandemia pós-moderna foi provocada pela gripe H1N1 em 2009, mas a grande pandemia causada pelo novo coronavírus, responsável pela Covid-19, é igualmente resultante de uma sociedade globalizada e baseada em informação; que só no Brasil, no período de 11 de março de 2019 até 30 de setembro de 2021, matou mais de 616 mil pessoas. (SILVA, 2003; GOMES E FERRAZ, 2012; GAZETA DO POVO, s.d).

De acordo com Carvalho (2020, p. 93), “a pandemia do coronavírus, da síndrome respiratória aguda grave 2 (SARS-CoV-2) é, como o nome sugere, o segundo surto da doença causada pela família de vírus coronaviridae em menos de 20 anos. Entre 2002 e 2004 mais de 8 mil pessoas foram infectadas e 774 morreram em 29 países e territórios de todo o mundo.”

As várias formas de contágio logo passaram a ser investigadas e amplamente divulgadas em todos os meios de comunicação. Os hábitos de higiene das pessoas, no que tange aos cuidados com os alimentos, consigo e com os outros indivíduos precisaram ser adequados aos novos padrões sanitários. Como citam Menezes e Pedrosa $(2021$, p. 2) "a mudança na rotina das pessoas incluiu desde o uso de máscaras de proteção e higienização das mãos de forma constante até o isolamento social, situação nunca vivida pela atual geração. Essa mudança de hábito, imposta pela necessidade de sobrevivência, impactou todas as áreas da economia em escala mundial".

Diante da nova realidade sanitária, situações do cotidiano que muitas vezes passavam despercebidas ganharam novamente a atenção devida por parte da sociedade. Dentre estas, estava a atenção com a qualidade dos produtos e a higiene nas feiras livres (FL), que representam um dos tipos de comércio mais antigos que se tem registro. Oferecem produtos alimentícios, produtos de reparos domésticos de pequeno porte, utensílios para animais domésticos, entre outros.

De acordo com Menezes (2019), as feiras livres (FL) possuem 03 categorias distintas: feira local ou feira de consumo dos compradores rurais, feira de distribuição e feira de 
abastecimento ou Feira de Consumidores Urbanos. Elas são de grande relevância socioeconômica, tendo como um dos fatores o fortalecimento da manutenção de empregos diretos e indiretos, em destaque o período da pandemia da Covid-19. (FREITAS, BARBOSA e SOARES, 2020).

Como orienta Franco, Landgraf e Pinto (2020, p. 6) "medidas preventivas simples relacionadas à higiene dos alimentos, do ambiente e das mãos devem ser implementadas por todos os atores da cadeia de produção alimentícia para manter o Sars-CoV-2 e outros microorganismos patogênicos longe do ambiente de produção e da mesa do consumidor".

Nesse contexto, as FL são reconhecidas como parte integrante desse processo e com muita responsabilidade, haja vista responder pelo abastecimento de grande parte da população.

Pelos estudos ora publicados, conseguiu-se identificar uma necessidade urgente e importante de melhoria nas FL da região Nordeste do Brasil, no que concerne às condições sanitárias antes da pandemia do novo coronavírus, e intensificadas no decorrer desta. A precariedade sanitária nas FL, principalmente da região Nordeste do Brasil, tem forte relação com o descaso do poder público diante das suas responsabilidades legais, bem como pela pequena consciência ambiental dos feirantes, o que resulta em hábitos de higiene que vão de encontro aos conceitos da educação ambiental.

A educação é um dos pilares fundamentais para a mudança de comportamento social. Dessa forma, Lima (2019, p. 9) compreende a educação ambiental como sinônimo da educação para a sustentabilidade e que o objetivo desta é "sensibilizar a população sobre as questões ambientais e possibilitar discussões que contribuam para a reflexão do indivíduo, corroborando com a busca e a construção de alternativas sociais, baseadas em princípios ecológicos, éticos e de justiça”.

Sendo assim, o arcabouço teórico ora apresentado serviu para embasar a pesquisa com a finalidade de responder se a pandemia da Covid-19 causou alguma mudança positiva no comportamento dos feirantes do Pátio Novo da Feira Livre (FL) de Afogados - Recife/PE, no tocante aos hábitos de limpeza e higiene. 


\section{MATERIAL E MÉTODO}

De acordo com Gil (2019), Lakatos e Marconi (2021) e Bardin (2006), o estudo caracterizou-se como de natureza aplicada, com o objetivo exploratório e descritivo, e estudo de caso único. Utilizou-se o método qualitativo-quantitativo e análise de conteúdo.

O locus da pesquisa foi o Pátio Novo da Feira Livre de Afogados (PNFLA), localizado entre as ruas General Christóvam Colombo de Souza e João Carlos Guimarães, no bairro de Afogados - Recife/PE, como pode ser observado na figura 1, onde se vê o mapa da Região Político Administrativa 05, com o PNFLA em destaque.

Figura 1 - Mapa da RPA 05, com destaque para a localização do PNFLA.

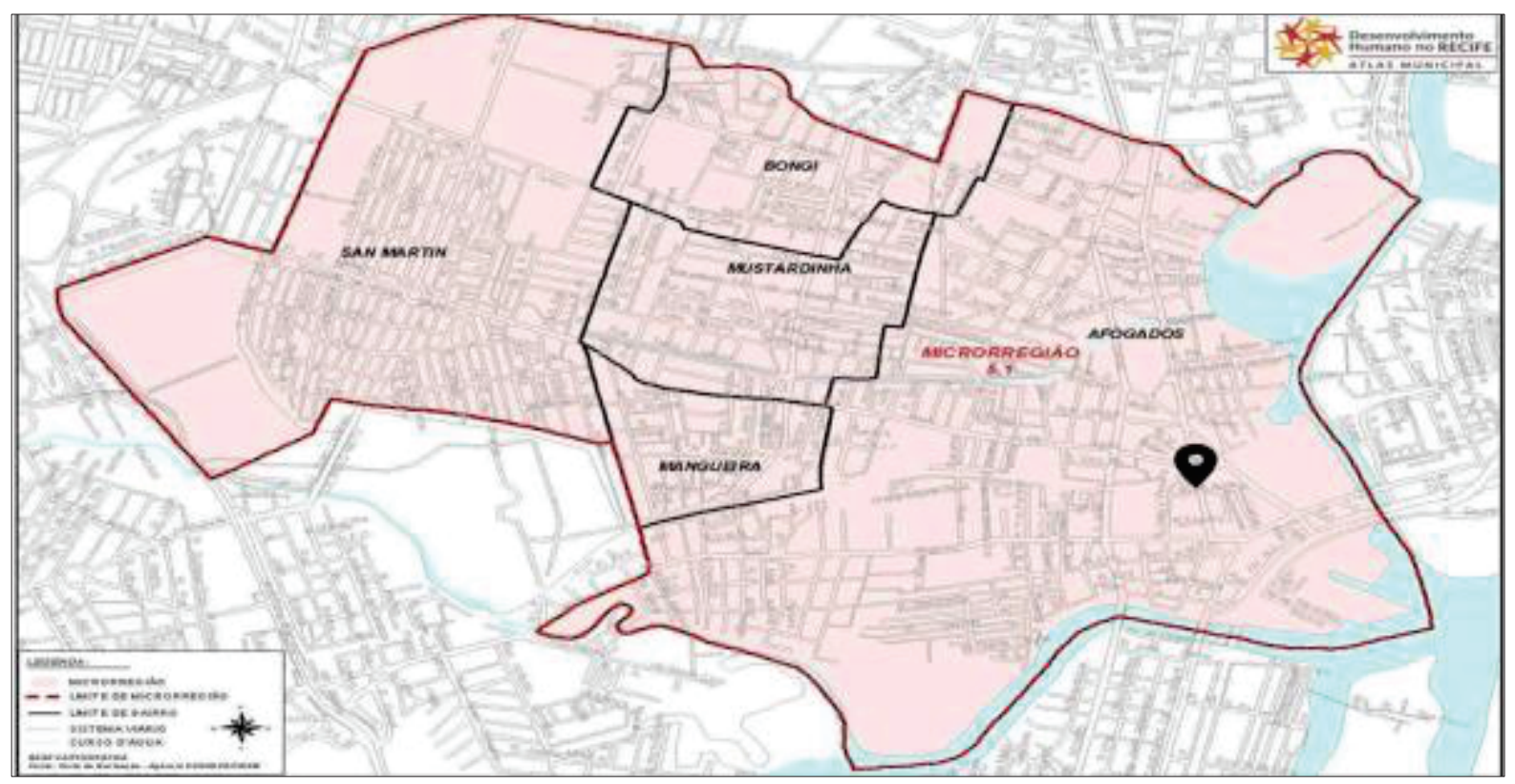

Fonte: Prefeitura da Cidade do Recife - Adaptado pelos autores.

A coleta de dados ocorreu entre os dias 23/10/21 a 21/11/21, em 03 visitas. Foram abordados 82 feirantes, dos quais 55 participaram da pesquisa respondendo aos questionários e 27 optaram por não participar. Todos foram abordados seguindo os protocolos de segurança sanitária orientados pelos órgãos competentes e um script pré-definido: primeiramente, fazendo uma saudação (bom dia, boa tarde); depois foi explicada de forma sucinta sobre o objetivo da pesquisa; e por fim, àqueles que se mostraram receptivos, foi mantido um diálogo mais aprofundado no qual explicou-se com mais detalhes os objetivos da pesquisa e mencionados os estudos anteriores.

A amostra contemplou exclusivamente os feirantes que comercializam nos bancos fixos, por estarem com sua situação regular perante a Prefeitura do Recife e possibilitando maior controle entre as recusas e aceites para participar da pesquisa. 
O questionário com perguntas objetivas e subjetivas foi o método de coleta de dados escolhido e estruturado em 03 partes: perfil socioprofissional com perguntas objetivas; conhecimento sobre o coronavírus e suas formas de contágio; e hábitos de higiene e limpeza do ambiente físico da feira livre antes e durante a pandemia com perguntas subjetivas, e utilizando o método de análise de conteúdo. (BARDIN, 2006).

\section{RESULTADOS}

Os resultados obtidos com a pesquisa foram discutidos nesta seção. Para responder aos objetivos específicos:

a) verificar a presença de material gráfico orientativo disponibilizado pelos órgãos sanitários do governo estadual e/ou municipal sobre o combate ao novo coronavírus e/ou as diversas formas de contágio;

b) identificar a forma de descarte dos resíduos secos e molhados por parte dos feirantes;

c) analisar a percepção dos feirantes sobre a relação entre a limpeza e conservação do ambiente físico e o combate ao novo coronavírus.

Para isso, foram necessárias 03 visitas ao Pátio Novo da Feira Livre de Afogados (PNFLA).

Verificou -se que dos 194 bancos existentes, apenas 82 deles estavam em funcionamento nas datas em que ocorreram as visitas, sendo a amostra constituída pelos 55 feirantes que aceitaram responder ao questionário, como pode ser verificado no quadro 01.

Quadro 01 - Visitas ao PNFLA e quantidade de Feirantes respondentes

\begin{tabular}{|c|c|c|c|c|}
\hline Feira & Horário & $\begin{array}{c}\text { Feirantes } \\
\text { Abordados }\end{array}$ & $\begin{array}{c}\text { Aceitaram } \\
\text { responder }\end{array}$ & $\begin{array}{c}\text { Recusaram } \\
\text { responder }\end{array}$ \\
\hline $23 / 10$ & $12 \mathrm{~h} 30$ & 25 & 18 & 07 \\
\hline $06 / 11$ & $15 \mathrm{~h} 00$ & 37 & 22 & 15 \\
\hline $21 / 11$ & $11 \mathrm{~h} 00$ & 20 & 15 & 05 \\
\hline
\end{tabular}

Fonte: os autores (2021).

Sobre a negativa em responder ao questionário, os feirantes apontaram vários motivos, como pode ser verificado no quadro 02 , que apresenta a categorização das respostas mais citadas.

A recusa dos feirantes no tocante a responder ao questionário foi categorizada da seguinte forma: os feirantes abordados na visita do dia 23/10 foram identificados com a letra "A", do dia 06/11 receberam a letra "B", e do dia 21/11 a letra "C", conforme exposto no quadro 2. 
Quadro 2 - Categorização sobre a disponibilidade e interesse em participar da pesquisa

\begin{tabular}{|c|c|r|}
\hline Expressões & Quant. & Algumas das Respostas obtidas por meio dos Feirantes \\
\hline Vergonha & 28 & $\begin{array}{r}\text { "Eu tenho vergonha de responder." (Feirante A 2) } \\
\text { "Deus me livre e guarde, tenho muita vergonha." (Feirante B 8) } \\
\text { "Não gosto de responder pesquisa, tenho vergonha." (Feirante C 5) }\end{array}$ \\
\hline Tempo & 25 & $\begin{array}{r}\text { "Eu 'tô' ocupado demais." (Feirante A 14) } \\
\text { "Eu nem posso falar com você agora." (Feirante B 9) }\end{array}$ \\
\hline Interesse & 21 & $\begin{array}{r}\text { "Não "tô' interessada em saber do que se trata." (Feirante A 8) } \\
\text { "Esse assunto é bom falar com a Prefeitura." (Feirante B 14) } \\
\text { "Ganha alguma coisa para responder?" (Feirante C 11) }\end{array}$ \\
\hline
\end{tabular}

Fonte: os autores (2021).

O perfil socioprofissional dos respondentes foi categorizado por meio de perguntas objetivas e composto dos seguintes dados:

a) Idade;

b) Nível de escolaridade;

c) Tempo de atuação como feirante;

d) Tipo de vínculo profissional que mantém com a feira.

Os resultados obtidos foram expostos nos gráficos 1,2, 3 e 4, apresentados a seguir: 
Gráficos 1 e 2 - Faixa etária e escolaridade dos respondentes
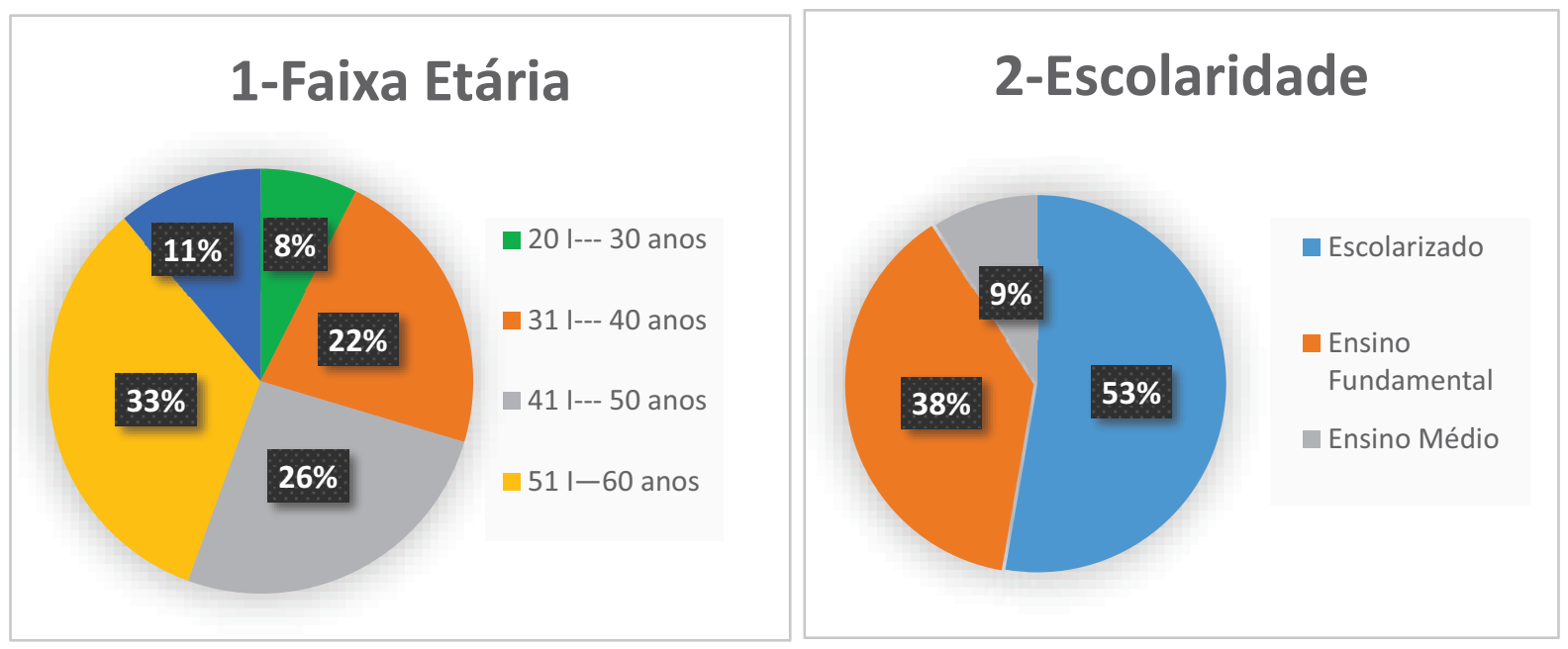

Fonte: os autores (2021)

Verificou -se, a partir dos gráficos apresentados, que 26\% dos respondentes tinham idade entre 41 e 50 anos, e 11\% tinham mais de 60 anos. Dos 55 respondentes, 53\% são escolarizados e apenas $9 \%$ concluíram o ensino médio.

Gráficos 3 e 4 - Tempo de atuação como feirante e tipo de vínculo

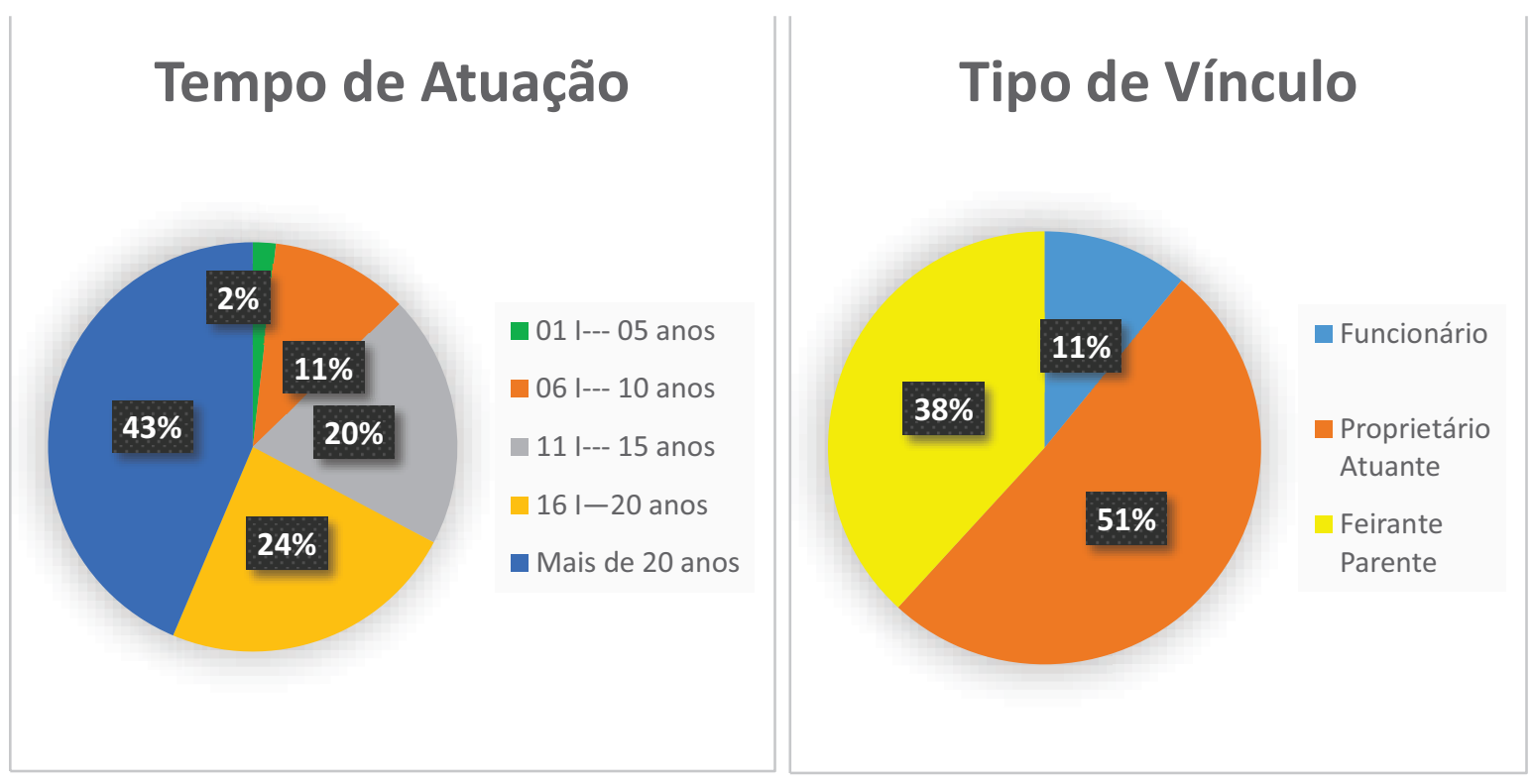

Fonte: os autores (2021)

Dos feirantes pesquisados, $43 \%$ atuam há mais de 20 de anos e $2 \%$ entre 01 e 05 anos. Os proprietários representaram $51 \%$ dos entrevistados, e $11 \%$ foi o percentual dos feirantes que são apenas funcionários. 
O conhecimento sobre o coronavírus e suas formas de contágio, e os hábitos de higiene e limpeza do ambiente físico da feira livre antes e durante a pandemia foram verificados por meio de perguntas subjetivas, tais como: você sabe o que é o novo coronavírus? Se sim, sabe as formas de contágio? Sabe dizer pelo menos uma forma de contágio? Se você sabe as formas de contágio do novo coronavírus, houve alguma mudança nos seus hábitos de higiene e limpeza aqui na feira?

A sequência de número 01 a 55 foi a forma utilizada para identificar os feirantes respondentes nos quadros 03 a 06, os quais contemplaram respostas subjetivas.

As definições sobre o que é coronavírus, na visão dos feirantes, foram compiladas e apresentadas no quadro 3 .

Quadro 3 - Você sabe o que é o novo coronavírus?

\begin{tabular}{|c|c|c|}
\hline Expressões & Quant. & Algumas das Respostas obtidas por meio dos Feirantes \\
\hline $\begin{array}{l}\text { Aquele } \\
\text { negócio }\end{array}$ & 08 & $\begin{array}{l}\text { “Aquele negócio que ‘tá’ matando o povo.” (Feirante 03) } \\
\text { “Aquele negócio que parece uma gripe.” ((Feirante 16) } \\
\text { “Aquele negócio que ‘tá' enchendo os hospital.” (Feirante 42) }\end{array}$ \\
\hline $\begin{array}{l}\text { Aquele } \\
\text { 'microbo' }\end{array}$ & 02 & $\begin{array}{l}\text { “Aquele 'microbo' que mata os 'velho'.” (Feirante 09) } \\
\text { “Aquele 'microbo' que não tem remédio.” (Feirante 35) }\end{array}$ \\
\hline $\begin{array}{l}\text { Aquela } \\
\text { doença }\end{array}$ & 45 & $\begin{array}{l}\text { “Aquela doença que mata muitas 'pessoa' de uma vez.” (Feirante 11) } \\
\text { “Aquela doença que não deixa a gente ir pra rua.” (Feirante 39) } \\
\text { “Aquela doença que tem que usar máscara.” (Feirante 55) }\end{array}$ \\
\hline
\end{tabular}

As respostas apresentadas no quadro 3 indicaram que os feirantes têm conhecimento sobre a existência do coronavírus, bem como do seu potencial de letalidade, ainda que não tenham reconhecido como "vírus" e sim como "micróbio".

O conhecimento sobre as formas de contágio pelo novo coronavírus é de grande importância para os feirantes, tendo em vista a contribuição da feira livre para a segurança alimentar da população, como pode ser verificado no quadro 4. 
Quadro 4 - Conhece as formas de contágio pelo novo coronavírus?

\begin{tabular}{|c|c|c|}
\hline Expressões & Quant. & Algumas das Respostas obtidas por meio dos Feirantes \\
\hline $\begin{array}{l}\text { Mais ou } \\
\text { menos }\end{array}$ & 07 & $\begin{array}{l}\text { “'Mai ou meno', tudo, tudo eu não sei.” (Feirante 08) } \\
\text { “’Rapai', mais ou 'meno', é complicado.” ((Feirante 26) } \\
\text { “Eu digo que conheço mais ou 'meno'.” (Feirante 49) }\end{array}$ \\
\hline Sei como é & 13 & $\begin{array}{l}\text { “Eu sei como é.” (Feirante 23) } \\
\text { “Sei como é pra mim, 'pros' ‘outro' não.” (Feirante 47) }\end{array}$ \\
\hline Conheço & 35 & $\begin{array}{l}\text { “Conheço demais minha gente.” (Feirante 14) } \\
\text { “Conheço muito ‘mermo'.” (Feirante 37) } \\
\text { “conheço de ‘vê' na internet.” (Feirante 51) }\end{array}$ \\
\hline
\end{tabular}

Fonte: os autores (2021)

Com base nas respostas apresentadas no quadro 4, percebeu-se que os feirantes têm pouca segurança ao afirmarem que conhecem ou desconhecem as formas de contágio pelo novo coronavírus. Fato que deveria preocupar tanto a população quanto o poder público.

Para confirmar se os feirantes sabiam as formas de contágio pelo novo coronavírus, foi pedido que explicassem "como" se dá o contágio, conforme apresentado no quadro 5.

Quadro 5 - Informe pelo menos uma forma de contágio?

\begin{tabular}{|c|c|r|}
\hline Expressões & Quant. & Algumas das Respostas obtidas por meio dos Feirantes \\
\hline Vento & 05 & "O vento que traz e entra na gente." (Feirante 05) \\
"A gente pega pelo vento." ((Feirante 29) \\
"Fariz
\end{tabular}

Fonte: os autores (2021) 
Todas as formas de contágio indicadas pelos feirantes são reconhecidas como verdadeiras, indicando que eles têm consciência bem definida de como podem ser contaminados ou contaminar outra pessoa.

Quadro 6 - Você mudou algum háb ito de higiene no seu banco e/ou a área onde você trabalha?

\begin{tabular}{|c|c|r|}
\hline Expressões & Quant. & Algumas das Respostas obtidas por meio dos Feirantes \\
\hline $\begin{array}{c}\text { Não tem } \\
\text { como }\end{array}$ & 29 & $\begin{array}{r}\text { "O que é a gente pode mudar? Não tem como." (Feirante 28) } \\
\text { "Eu tentei mudar alguma coisa, mas não tem como." ((Feirante 41) } \\
\text { "Não tem como mudar nada, ninguém aqui conseguiu." (Feirante 53) }\end{array}$ \\
\hline $\begin{array}{c}\text { Saquinhos } \\
\text { de redinha }\end{array}$ & 09 & $\begin{array}{r}\text { "Eu 'tô' fazendo os saquinhos de redinha." (Feirante 12) } \\
\text { "Com saquinho de redinha o freguês não mexe." (Feirante 19) }\end{array}$ \\
\hline $\begin{array}{c}\text { Não } \\
\text { precisa }\end{array}$ & 11 & $\begin{array}{r}\text { "Não precisa, tem que lavar quando chegar em casa." (Feirante 06) } \\
\text { "Não precisa, já vem da Ceasa sujo." (Feirante 24) }\end{array}$ \\
& "Não precisa, o povo come as coisas aqui e nem lava." (Feirante 38) \\
\hline
\end{tabular}

Fonte: os autores (2021)

Ao analisar as respostas dos feirantes expostas no quadro 6, percebeu-se que apenas 01 mudança foi realizada em toda forma de trabalho, limpeza e higiene do ambiente físico da feira. Vincula-se esse cenário à ausência de orientação e acompanhamento técnico relatado pelos feirantes.

Foi perguntado para todos os feirantes entrevistados se houve alguma orientação por parte da Prefeitura ou órgão sanitário. Todos eles foram unânimes em afirmar que não houve qualquer tipo de orientação além dos cartazes fixados em poucos pontos da feira. 
Figura 01a - Descarte de máscara de proteção e resíduos Figura 01b - Reaproveitamento de alimentos

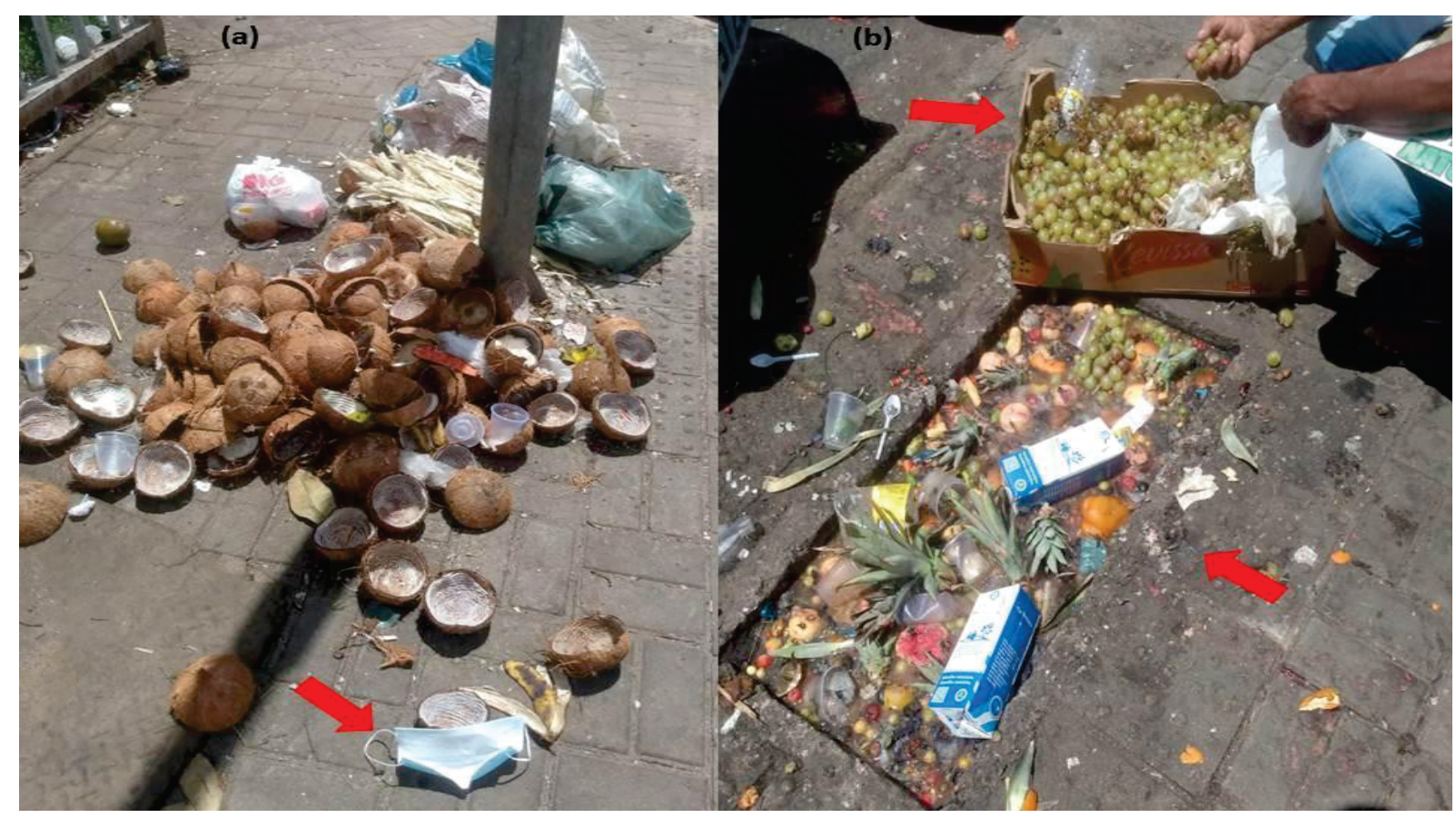

Fonte: os autores (2021)

Pode ser verificado na figura 1 a o descarte indevido de resíduo orgânico e não orgânico. Chama-se a atenção para a máscara facial de uso não profissional descartada no chão, juntamente com os demais resíduos, situação avessa ao que que orienta os órgãos de saúde como o Centro Estadual de Vigilância em Saúde do Rio Grande do Sul (2020): “esses materiais, após utilizados, não devem ser colocados diretamente na lixeira, mas embalados em saco plástico, e também não devem ser misturados com materiais recicláveis".

A figura $1 \mathrm{~b}$ registrou o momento em que um catador de material reciclável es tava separando as frutas que ainda tinham condições para consumo, dispostas em uma caixa colocada no chão, ao lado de um esgoto aberto e repleto de resíduos orgânicos e não orgânicos. Uma situação desnecessária e comum na rotina das FL. 
Figura 02a - Presença de animais na área interna do PNFLA

Figura 02b - Exposição de resíduos orgânicos e não orgânicos

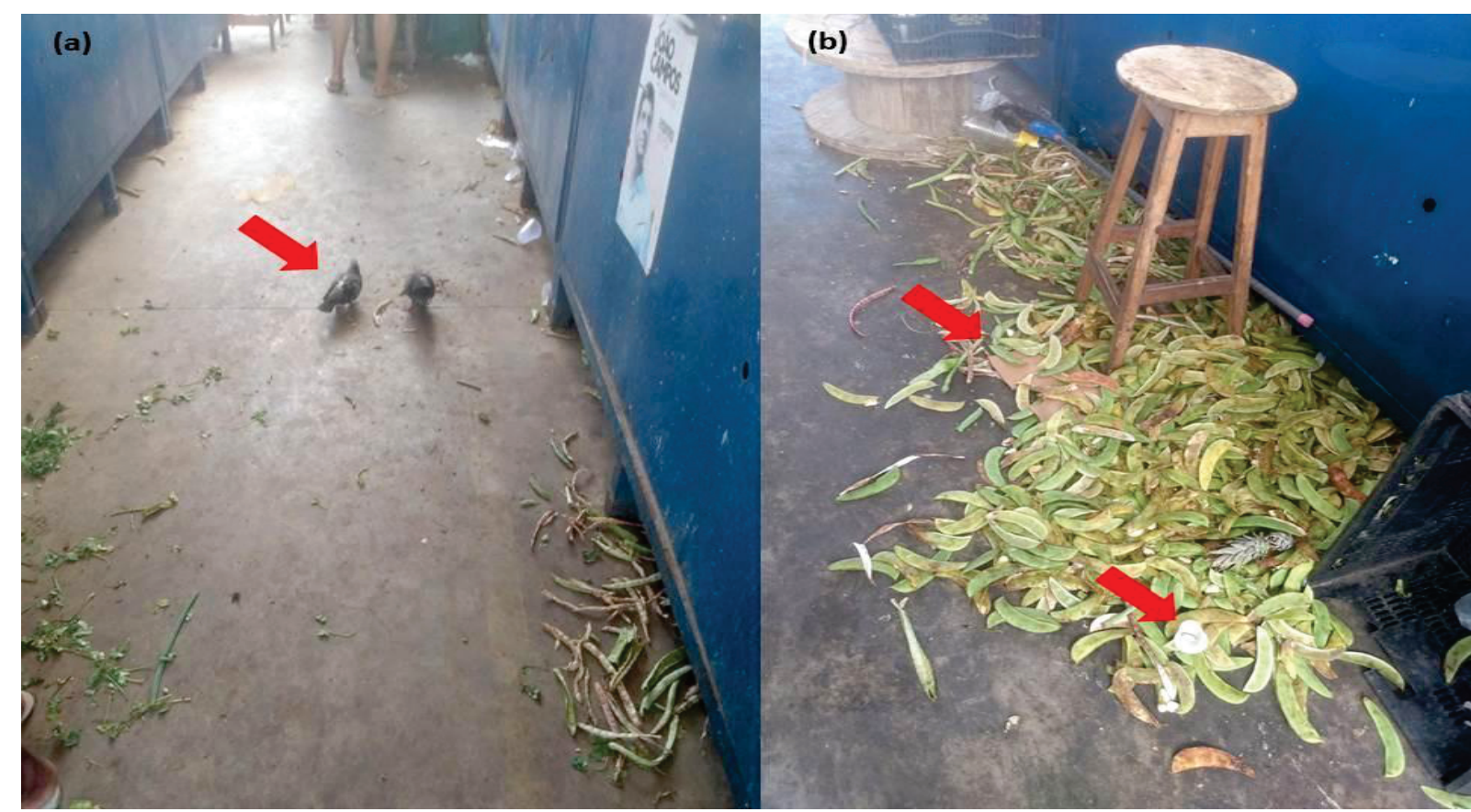

Fonte: os autores (2021)

Nas figuras 02a e 02b foi registrada a presença de aves na área interior da feira, transitando entre os bancos de forma livre e muito próximo dos alimentos e resíduos, que mais uma vez confirma a difícil realidade no que tange às condições de higiene e limpeza do PNFLA. Vale destacar que os coletores de resíduos disponibilizados pela Prefeitura do Recife encontravam-se a menos de 150 metros do local apresentado nas figuras 02 .

Se os coletores são disponibilizados pela Prefeitura, por qual motivo o PNFLA tem os resíduos descartados erroneamente, mesmo com a presença do novo coronavírus ainda causando o óbito de tantas pessoas?

Nessa perspectiva, indica-se à Prefeitura do Recife atuar de forma mais ativa em ações de conscientização e educação ambiental, bem como em boas práticas na manipulação de alimentos, objetivando melhorar o comprometimento dos feirantes com a higiene e limpeza do ambiente físico do PNFLA.

\section{CONCLUSÃO}

A Feira Livre (FL) está presente no cotidiano da sociedade e é um ambiente de muita movimentação, seja de pessoas quanto de produtos diariamente, com isso possui alto potencial para o contágio pelo novo coronavírus, que se destaca nesse momento da primeira pandemia do século XXI. Dessa forma, observou-se que os feirantes do PNFLA têm conhecimento sobre os 
riscos e as formas de contágio, porém, isso não foi suficiente para mudar a rotina deles no que tange à limpeza e conservação do ambiente físico do PNFLA. As pessoas permanecem aglomerando e pouquíssimos clientes e feirantes foram vistos utilizando máscaras de proteção.

Uma iniciativa simples e prática adotada por poucos foi o ensacamento das frutas e legumes em "saquinhos de redinha", como é chamado o saco rede de plástico, o qual evita a manipulação direta dos produtos.

As pessoas que trabalham na feira livre não tiveram suporte técnico e sanitário satisfatório por parte da Prefeitura do Recife para enfrentar a pandemia. Essa é a maior constatação desse trabalho.

Então, a pandemia só agravou o caos ambiental presente nas feiras livres. E isso só confirma o resultado apresentado neste estudo, bem como em vários outros publicados pelos autores.

Para que as FL continuem existindo, é muito importante que haja um projeto robusto com foco na melhoria da consciência e educação ambiental dos feirantes para que possa haver a mudança de comportamento ambiental nesses espaços.

A fragilidade sanitária nas feiras livres compromete a continuidade desse símbolo de cultura e tradição, além da manutenção de tantas famílias que de lá tiram seus sustentos.

É preciso que haja mais censos, empenho dos governantes de todas as esferas e enxergar a feira como um lugar tão importante quanto parques, praças e praias no controle da pandemia.

Dessa forma, sugere-se aos órgãos competentes adotar o plano estratégico apresentado por Menezes (2019), no qual inclui diversas ações que se utilizadas poderão melhorar significativamente a consciência ambiental dos feirantes do PNFLA.

Como proposta para pesquisas futuras, propõem-se expandir o estudo para outras feiras livres da região metropolitana do Recife e de outras capitais.

\section{REFERÊNCIAS}

BARDIN, L. (2006). Análise de conteúdo. (L. de A. Rego \& A. Pinheiro, Trads.). Lisboa: Edições 70. (Obra original publicada em 1977).

BRASIL. Ministério do Desenvolvimento Social. Pesquisa Sobre Segurança Alimentar e Nutricional Começa em Agosto, 2015. Disponível em: https://www.sna.agr.br/mapeamentodo-mds-identifica-em-torno-de-64-mil-feiras-livres-e-agroecologicas-em-todo-pais/. Acesso em: 30 nov. 2021.

CARVALHO, R. A. Doenças Infecciosas Emergentes na Fronteira do Desmatamento. In: YOUNG, C. E. F.; MATHIAS, J. F. C. M. Covid-19, Meio Ambiente e Políticas Públicas São Paulo: Hucitec, 2020. Parte II. pág. 93 - 100. Disponível em: 
http://www.huciteceditora.com.br/ imagens/_downloads/Covid19\%20Meio\%20Ambiente\%20e\%20Politicas\%20Publicas.pdf. Acesso em: 28 nov. 2021.

FRANCO, B. D. G. de M.; LANDGRAF, M.; PINTO, U. M. Alimentos, Sars-CoV-2 e Covid19: contato possível, transmissão improvável. Estudos Avançados, [S. 1.], v. 34, n. 100, p. 189-202, 2020. DOI: 10.1590/s0103-4014.2020.34100.012. Disponível em: https://www.revistas.usp.br/eav/article/view/178768. Acesso em: 02 dez. 2021.

FREITAS, E. P.; BARBOSA, A. F.; SOARES, O. M. S. O Impacto da Pandemia Sobre As Feiras Livres: Caso Corumbá-MS. v. 3 n. 2 (2020): Espaço Tempo Midiático: Edição Especial Covid-19. Disponível em: https://sistemas.uft.edu.br/periodicos/index.php/ midiaticos/issue/view/ISSN\%20-\%202526-5725. Acesso em: 30 nov. 2021.

GAZETA DO POVO. Números do Coronavírus (s.d). Disponível em: https://especiais.gazetadopovo.com.br/coronavirus/numeros/. Acesso em: 07 dez. 2021.

GIL, A. C. Métodos e técnicas de pesquisa social. 7. ed. São Paulo: Atlas, 2019.

GOMES, I. M. A. M; FERRA, L. M. R. Ameaça e controle da gripe A(H1N1): uma análise discursiva de Veja, IstoÉ e Época. Rev. Saúde e Sociedade, Volume: 21, Número: 2 (2012). p.302-313. DOI: 10.1590/S0104-12902012000200005. Disponível em: https://www.revistas.usp.br/sausoc/article/view/48709. Acesso em: 04 nov. 2021.

LAKATOS, E. M.; MARCONI, M. A. Metodologia do Trabalho Científico. 9. ed.São Paulo: Atlas, 2021.

LIMA, L. O. Práticas Pedagógicas em Educação Ambiental nas Escolas Públicas Municipais do Recife. Dissertação de Mestrado apresentada ao Programa de Pós-Graduação em Gestão do Desenvolvimento Local Sustentável da Universidade de Pernambuco, 2019. Disponível em: https://w1files.solucaoatrio.net.br/atrio/upegdls_upl//THESIS/223/lcia de oliveira_dissertao_final_20191218095619929.pdf. Acesso em: 25 out. 2021.

MENEZES, M. F. Subsídios para a Implantação dos 5R's da Sustentabilidade na Feira Livre de Afogados - Recife/PE. Dissertação de Mestrado apresentada ao Programa de PósGraduação em Gestão do Desenvolvimento Local Sustentável da Universidade de Pernambuco, 2019. Disponível em: https://w1files.solucaoatrio.net.br/atrio/upegdls_upl//THESIS/209/dissertao_magali_ferreira_de_menezes_2019072611330872.pdf. Acesso em: 20 out. 2021.

MENEZES, M. F.; FREITAS, N. M. V.; PEDROSA, F. J. A. As Feiras Livres do Nordeste: uma Análise Acerca da Higiene e Conservação do Ambiente Físico (no prelo).

MENEZES, M. F.; PEDROSA, F. J. A. Muda-se de Lugar, Mantém-se os Hábitos: Estudo Sobre a Feira Livre do Bairro de São José- Recife/PE. Revista Equador (UFPI), Vol. 10, N 1, Ano, 2021, p. 287 - 302. Disponível em:

https://revistas.ufpi.br/index.php/equador/article/view/12755/7485. Acesso em: 30 nov. 2021.

RECIFE - MAPA DA RPA 05. Disponível em: (https://www.recife.pe.gov.br/pr/secplanejamento/pnud2005/micro\%205_1.jpg). Acesso em: 10 nov. 2021. 
RIO GRANDE DO SUL. SECRETARIA DE SAÚDE. Saiba como descartar e higienizar corretamente as máscaras de proteção. Disponível em: https://saude.rs.gov.br/saiba-comodescartar-e-higienizar-corretamente-as-mascaras-de-protecao. Acesso em: 20 dez. 2021.

SILVA, L. J. A Globalização da doença. Rev. Saúde Pública, vol. 37 n. 3. DOI: 10.1590/S0034-89102003000300001.

Disponível

em: https://www.scielo.br/j/rsp/a/XX6YtN4jjqVjNdFMsJMPMRL/?lang=pt Acesso em: 06 dez. 2021. 